\title{
Features Associated With Contagiousness Among COVID-19 Cases in Shanghai, China
}

\section{Dechuan Kong}

Shanghai Municipal Center for Disease Control and Prevention

\section{Qiwen Fang}

Shanghai Municipal Center for Disease Control and Prevention

\section{Huanyu Wu}

Shanghai Municipal Center for Disease Control and Prevention

\section{Linjie $\mathrm{Hu}$}

Fudan University School of Public Health

\section{Abram L. Wagner}

University of Michigan

\section{Yihan Lu}

Fudan University School of Public Health

\section{Yaxu Zheng}

Shanghai Municipal Center for Disease Control and Prevention

\section{Xiaohuan Gong}

Shanghai Municipal Center for Disease Control and Prevention

Yiyi Zhu

Shanghai Municipal Center for Disease Control and Prevention

\section{Bihong Jin}

Shanghai Municipal Center for Disease Control and Prevention

\section{Wenjia Xiao}

Shanghai Municipal Center for Disease Control and Prevention

\section{Shenghua Mao}

Shanghai Municipal Center for Disease Control and Prevention

\section{Sheng Lin}

Shanghai Municipal Center for Disease Control and Prevention

\section{Ruobing Han}

Shanghai Municipal Center for Disease Control and Prevention

\section{Xiao Yu}

Shanghai Municipal Center for Disease Control and Prevention

\section{Peng Cui}

Shanghai Municipal Center for Disease Control and Prevention Chenyan Jiang 
Shanghai Municipal Center for Disease Control and Prevention

Hao Pan ( $\square$ panhao_scdc@126.com )

Shanghai Municipal Center for Disease Control and Prevention

Xiaodong Sun

Shanghai Municipal Center for Disease Control and Prevention

\section{Research Article}

Keywords: coronavirus, China, disease transmission, outbreak control, urban

Posted Date: May 25th, 2021

DOI: https://doi.org/10.21203/rs.3.rs-540906/v1

License: (c) (i) This work is licensed under a Creative Commons Attribution 4.0 International License. Read Full License 


\section{Abstract}

Background: Little is known about the characteristics of those who transmit SARS-CoV-2 infection vs those

who do not, but this information could inform disease control policies. This study described the features of clusters in the first wave of COVID-19 in Shanghai and compared contagiousness by clinical and health care risk factors.

Methods: In this retrospective cohort study of cases in Shanghai in January and February 2020, cases with successive generations were considered to be "contagious." Characteristics of contagious and noncontagious cases were compared in log-binomial models that also adjusted for age and sex.

Results: Between January 21 and February 17, 2020, 333 cases of COVID-19 were reported in Shanghai across 28 known infection chains. Contagiousness was higher among cases with a sore throat (risk ratio [RR]: $3.41,95 \% \mathrm{Cl}: 1.59,7.35, \mathrm{P}=0.0051$ ), and those with heart disease (RR: $2.06,95 \% \mathrm{Cl}: 0.72,5.90)$. Delays in diagnosis were also associated with higher risk of contagiousness. Having $\geq 2$ medical visits before diagnosis was associated with 4.46 times higher risk of contagiousness ( $95 \% \mathrm{Cl}: 2.03,9.83, \mathrm{P}=0.0002)$, and there was a non-significant increase in risk with increasing numbers of days between disease onset and isolation (for each day, RR: $1.08,95 \% \mathrm{Cl}: 1.01,1.16, \mathrm{P}=0.1734$ ).

Conclusions: Individuals with mild COVID-19 symptoms in the upper respiratory tract may still be contagious, and such individuals should be prioritized for early diagnosis and isolation to limit further chains of transmission.

\section{Background}

The novel coronavirus disease (COVID-19) [1] has attracted intense global attention since the beginning of the outbreak in Wuhan, China, in December 2019 [2]. The World Health Organization (WHO) declared the outbreak to be a Public Health Emergency of International Concern on January 30 and a pandemic on March 11 [3].

Clusters of COVID-19 cases have been reported worldwide, such as on the cruise ship Diamond Princess in Japan [4], among believers in the Korean Shincheonji church [5], and in prisons in 3 provinces in China [6]. In China, most cases have a traceable source of infection and are part of clusters. The clustered cases account for $50 \%-80 \%$ in all confirmed cases and have been the focus of outbreak control [7].

Information regarding the epidemiological and clinical characteristics of COVID-19 clusters is limited. But this information is key for control of the spread of COVID-19. Understanding what clinical features or conditions are most associated with contagiousness can help policymakers and public health officials prioritize testing, contact tracing, and isolation efforts. This study collects information from all confirmed COVID-19 cases in Shanghai between January 21 and February 17, 2020, and separated them into those with subsequent chains of transmission (i.e., "contagious") and those without. This study describes the features of clusters in the first wave of COVID-19 in Shanghai and compared contagiousness by clinical and health care risk factors. 


\section{Methods}

\section{Study design and data source}

In this cross-sectional study, we conducted a descriptive and exploratory analysis of clusters of COVID-19 confirmed cases in Shanghai. All confirmed cases, diagnosed on the basis of the working national protocol [8], and reported through the China Information System for Disease Control and Prevention before February 17, 2020, were enrolled. According to the cluster investigation technical guidelines in China [9], a cluster is $\geq 2$ confirmed cases or asymptomatic infected persons found in a small area (such as households, workplaces, vehicles, etc.) within 14 days. This definition considers the possibility of human-to-human transmission caused by close contact or exposed to a common infection source.

Individual data from filed investigation reports through interviews by CDC staff and medical records were entered and managed in EpiData version 3.1 (EpiData Association, Odense, Denmark). Cases were coded by unique identification numbers and were de-duplicated prior to analysis. Variables of interest included demographic information (age, gender, occupation), initial symptoms at onset (self-reported by the cases during epidemiological investigation), comorbid condition (including body mass index (BMI)), severity of illness [10], and indicators at first clinical visit.

\section{Statistical analysis and study definitions}

\section{Epidemiological description of clusters in Shanghai}

We graphed epidemic curves of clusters by both date of illness onset and date of report. Time of cluster formation was defined as the time when the second case involved fell ill or was identified. Key dates relating to important events (i.e. lockdown of Wuhan, Chinese Spring Festival, launch of first-class response in Shanghai, announcement of work resumption in Shanghai) were also labelled to explore their influence on the spread of the outbreak.

\section{Analysis on the transmission features of clusters}

Using information gleaned about the relationship between clustered cases, we divided the clusters into 4 types: familial, occupational, social and mixed.

Analysis of the serial interval (i.e. the average time between onset of cases in a chain of transmission) was conducted based on explicit chains we selected according to the following criteria [9]: (1) Contact with one case of the previous generation within 1-14 days before the onset of illness; (2) No history of trips or residency related to Wuhan and surrounding areas or other communities where confirmed cases existed; (3) No other potential exposures, such as hospital visits. Cases were excluded if they had exposure to two or more cases of the previous generation within 1-14 days before onset.

Cases were categorized into those who were contagious (i.e., had a successive generation) and those who did not. In a multivariable log-binomial regression model, these were adjusted for age and sex. Only those risk factors which had at least 5 contagious cases been considered. Each risk factors were put in a 
separate regression model, and p-values across models were adjusted for multiple testing with the HolmBonferroni method. Significance was assessed at an $a=0.05$ level. Data were analyzed in SAS version 9.4 (SAS Institute, Cary, NC). Figures in the study were progressing by R (v4.0.4, R Foundation for Statistical Computing, Vienna, Austria. URL https://www.R-project.org/) and Excel 2016 (Microsoft Office, Redmond, WA, USA).

\section{Ethics approval}

This study was reviewed and approved by the Shanghai Municipal CDC Ethical Review Committee. Cases were not given an informed consent form as the data were collected as part of on-going public health surveillance.

\section{Results}

A total of 333 cases of COVID-19 were reported in Shanghai between January 21 and February 17, 2020. Most $(186,56 \%)$ of cases occurred in clusters, with 61 clusters being reported in this time period. Most clusters $(64 \%, 39 / 61)$ only had two cases, with a declining proportion held by clusters of more cases: $15 \%$ $(9 / 61), 11 \%(7 / 61)$ and $10 \%(6 / 61)$ for clusters of 3,4 , and $\geq 5$ cases, respectively.

\section{Epidemiological description of clusters in Shanghai}

By date of onset, clusters began to occur sporadically from January 3 , reaching a peak (8 clusters) on January 29 and then gradually decreasing. By date of report, clusters began to be identified on January 21 and then declined after reaching the peak (8 clusters) on January 31. We found the report peak occurred about 2 days after the onset peak. After accumulatively reporting 3 clusters on January 24, also the first day of the Chinese Spring Festival (Chinese New Year) holiday, the Shanghai government launched what they termed a first-class response, and a decline in the clusters was observed about 7 days later by onset date. After considering the increased risk of COVID-19 transmission during the massive human migration across provinces that occurs during the holiday (January 24- February 2), the Chinese national government delayed the start of work to February 10 (Fig. 1).

A total of 83 cases $(45 \%, 83 / 186)$ were locally infected in Shanghai, and 89 cases were infected in five other provinces in China, including 39\% (72/186) in Hubei, 5\% (9/186) in Jiangsu, 3\% (5/186) in Anhui, 1\% $(2 / 186)$ in Shandong, and $1 \%(1 / 186)$ in Heilongjiang; Seven cases $(4 \%, 7 / 186)$ were infected in foreign countries (four in Europe and three in Asia); The location of infection for 7 cases $(4 \%, 7 / 186)$ were not able to be determined. Of the 103 cases who were infected outside of Shanghai, 33\% (34/103) arrived in Shanghai by aircraft, $29 \%$ (30/103) by high-speed railway/bullet train, and $25 \%(26 / 13)$ by driving private cars.

\section{Transmission features of clusters}

An analysis of the relationship among cases involved in the 61 clusters revealed that familial transmission was predominant, accounting for $84 \%$ (51/61) of clusters (Fig. 2). Exposure in workplaces was responsible 
for 1 cluster of 3 cases. Three clusters $(5 \%, 3 / 61)$ occurred during social activities (e.g., on the same tour group, real estate transactions, taxi rides), involving 2 cases each. Additionally, 6 clusters $(10 \%, 6 / 61)$ were not able to be identified into one type of cluster; all these mixed clusters involved familial transmission.

The serial interval was calculated for 28 clear transmission chains we selected from 61 clusters, excluding 2 chains with equivocal onset time. We found that the serial interval in Shanghai ranged from -1.83 to 14.63, and the median and IQR were $5.50(2.47,11.47)$ (Fig. 3). Two peaks emerged at 1-3 days and 1113 days. Two chains with onset of subsequent generations earlier than the last generation $(1.83,0.5$ days) were observed, indicating transmission during the incubation period. We observed a large variability in serial interval when two generations contacted $1-2$ times instead of having continuous exposure $(\geq 3$ or more days, such as when living together), i.e. 14.63 days (contacted twice), 12.63 days (contacted once), 12.46 days (contacted once), 2.08 days (contacted once), 1.63 days (contacted once). The serial interval in the other 23 chains with continuous exposure ranged from -1.83 to 12.83 , median and IQR were 5.05 $(2.50,9.33)$

\section{Development trends of clustered cases under specific policies}

In the early stage, clustered cases were mainly imported from Hubei province, supplemented by local infections in Shanghai; imported cases from other regions were relatively scarce. Following the policies locking down Wuhan on January 23 and the initiation of a first-class response to public health emergencies in Shanghai on January 24, clustered cases imported from Hubei gradually declined after reaching the onset peak on January 28-30. The reported peak was observed to be delayed by 1-3 days. Imported cases from Hubei province were rarely identified in clusters past 14 days (one incubation period) after adopting the effective prevention and control measures. At this point, locally infected cases began to dominate.

The means of identifying cases are presented in Fig. 4 . Among 83 local clustered cases, cases were mainly identified through community screening $(28 \%, 23 / 83)$, collective isolation points $(16 \%, 13 / 83)$, and personal clinical visit $(57 \%, 47 / 83)$. Clustered cases started to be identified through active community screening and collective isolation points from January 24 and January 31 respectively, and the proportion of cases identified through personal clinical visits gradually decreased. Besides these three means of detecting cases, imported cases could also be identified through checkpoint examinations. Since January 26 , a total of 6 cases had been found at checkpoints. Individual clinical visits still dominated for imported cases (community screening: $24 \%, 23 / 96$; collective isolation point: $7 \%, 7 / 96$; checkpoint: $6 \%, 6 / 96$, individual clinical visit: 63\%,60/96).

\section{Individual risk factors of contagiousness}

We separated individuals into those who were non-contagious cases and those contagious, i.e., having successive generations (Table 1). Contagiousness was higher among cases with a sore throat (risk ratio [RR]: 3.41, 95\% Cl: 1.59, 7.35, P = 0.0051), and those with heart disease (RR: $2.06,95 \% \mathrm{Cl}: 0.72,5.90$ ). Delays in diagnosis were also associated with higher risk of contagiousness. Having $\geq 2$ medical visits before diagnosis was associated with 4.46 times higher risk of contagiousness ( $95 \% \mathrm{Cl}$ : 2.03, 9.83, P = 
0.0002), and there was a non-significant increase in risk with increasing numbers of days between disease onset and isolation (for each day, RR: 1.08, 95\% Cl: 1.01, 1.16, P = 0.1734). 
Table 1

Epidemiological and clinical characteristics of sporadic cases and clustered cases

\begin{tabular}{|c|c|c|c|c|}
\hline & $\begin{array}{l}\text { Count } \\
\text { (col. \%) }\end{array}$ & $\begin{array}{l}\text { Contagious case } \\
\text { (row \%) }\end{array}$ & $\begin{array}{l}\text { Risk ratio }{ }^{a} \\
(95 \% \mathrm{Cl})\end{array}$ & $\begin{array}{l}\text { P } \\
\text { value }\end{array}$ \\
\hline \multicolumn{5}{|l|}{$\mathrm{Age}^{\mathrm{c}}$} \\
\hline $0-20$ years & $14(4 \%)$ & $0(0 \%)$ & & \\
\hline 20-39 years & $106(32 \%)$ & $10(9 \%)$ & & \\
\hline $40-59$ years & 107 (32\%) & $6(6 \%)$ & & \\
\hline $60-88$ years & $106(32 \%)$ & $11(10 \%)$ & & \\
\hline \multicolumn{5}{|l|}{ Gender } \\
\hline Male & $173(52 \%)$ & $12(7 \%)$ & & \\
\hline Female & $160(48 \%)$ & $15(9 \%)$ & & \\
\hline \multicolumn{5}{|l|}{ Initial symptoms } \\
\hline Fever & $207(62 \%)$ & $18(9 \%)$ & $\begin{array}{l}1.17(0.55 \\
2.52)\end{array}$ & 1 \\
\hline Chill & $20(6 \%)$ & $1(5 \%)$ & & \\
\hline Dry cough & $106(32 \%)$ & $9(8 \%)$ & $\begin{array}{l}1.10(0.51 \\
2.36)\end{array}$ & 1 \\
\hline Productive cough & $29(9 \%)$ & $2(7 \%)$ & & \\
\hline Sore throat & $31(9 \%)$ & $7(23 \%)$ & $\begin{array}{l}3.41 \\
7.35)\end{array}$ & 0.0051 \\
\hline Headache & $30(9 \%)$ & $1(3 \%)$ & & \\
\hline Dizziness & $8(2 \%)$ & $1(13 \%)$ & & \\
\hline Nasal obstruction & $13(4 \%)$ & $0(0 \%)$ & & \\
\hline
\end{tabular}

a Models adjusted for age group and gender, but no other risk factor. Only risk factors with $\geq 5$ contagious cases were considered.

${ }^{b}$ P-value corrected for multiple testing through the Holm-Bonferroni method.

${ }^{\mathrm{C}}$ mean: 48.3 years, standard deviation: 17.6 years

${ }^{\mathrm{d}}$ mean: 23.9 , standard deviation: 4.2

e mean: 1.5 visits, standard deviation: 0.9 visits

${ }^{f}$ mean: 5.0 days, standard deviation: 4.3 days 


\begin{tabular}{|c|c|c|c|c|}
\hline & $\begin{array}{l}\text { Count } \\
\text { (col. \%) }\end{array}$ & $\begin{array}{l}\text { Contagious case } \\
\text { (row \%) }\end{array}$ & $\begin{array}{l}\text { Risk ratioa } \\
(95 \% \mathrm{Cl})\end{array}$ & $\begin{array}{l}P \\
\text { value }\end{array}$ \\
\hline Runny nose & $19(6 \%)$ & $4(21 \%)$ & & \\
\hline Muscle soreness & $25(8 \%)$ & $3(12 \%)$ & & \\
\hline Sore joints & $25(8 \%)$ & $3(12 \%)$ & & \\
\hline Weakness & $40(12 \%)$ & $4(10 \%)$ & & \\
\hline Chest stuffiness & $7(2 \%)$ & $2(29 \%)$ & & \\
\hline \multicolumn{5}{|l|}{$B M I^{d}$} \\
\hline Underweight & 35 (11\%) & $1(3 \%)$ & $\begin{array}{l}0.61(0.08, \\
4.46)\end{array}$ & 1 \\
\hline Normal & $189(57 \%)$ & $12(6 \%)$ & ref & \\
\hline Overweight & 109 (33\%) & $14(13 \%)$ & $\begin{array}{l}2.28(1.08, \\
4.83)\end{array}$ & 0.2184 \\
\hline \multicolumn{5}{|l|}{ Comorbid condition } \\
\hline Diabetes & $28(8 \%)$ & $6(21 \%)$ & $\begin{array}{l}3.40(1.29, \\
8.92)\end{array}$ & 0.0645 \\
\hline High blood pressure & $64(19 \%)$ & $9(14 \%)$ & $\begin{array}{l}2.21(0.93, \\
5.23)\end{array}$ & 0.5704 \\
\hline Heart disease & $24(7 \%)$ & $4(17 \%)$ & $\begin{array}{l}2.06(0.72, \\
5.90)\end{array}$ & 0.0002 \\
\hline Lung disease & $5(2 \%)$ & $1(20 \%)$ & & \\
\hline \multicolumn{5}{|l|}{ Clinical manifestation } \\
\hline Mild (non-pneumonia) & $15(5 \%)$ & $1(7 \%)$ & $\begin{array}{l}0.96(0.13, \\
6.98)\end{array}$ & 1 \\
\hline Mild (pneumonia) & $293(88 \%)$ & $20(7 \%)$ & ref & \\
\hline
\end{tabular}

a Models adjusted for age group and gender, but no other risk factor. Only risk factors with $\geq 5$
contagious cases were considered.
b P-value corrected for multiple testing through the Holm-Bonferroni method.
${ }^{c}$ mean: 48.3 years, standard deviation: 17.6 years
d mean: 23.9 , standard deviation: 4.2
${ }^{\text {e }}$ mean: 1.5 visits, standard deviation: 0.9 visits
${ }^{f}$ mean: 5.0 days, standard deviation: 4.3 days




\begin{tabular}{|c|c|c|c|c|}
\hline & $\begin{array}{l}\text { Count } \\
\text { (col. \%) }\end{array}$ & $\begin{array}{l}\text { Contagious case } \\
\text { (row \%) }\end{array}$ & $\begin{array}{l}\text { Risk ratio a } \\
(95 \% \mathrm{Cl})\end{array}$ & $\begin{array}{l}P \\
\text { value }\end{array}$ \\
\hline Severe & $9(3 \%)$ & $2(22 \%)$ & $\begin{array}{l}3.78(1.01 \\
14.21)\end{array}$ & 1 \\
\hline Critically severe & $16(5 \%)$ & $4(25 \%)$ & $\begin{array}{l}4.96(1.66, \\
14.85)\end{array}$ & 0.0168 \\
\hline \multicolumn{5}{|l|}{ Seeking medical help } \\
\hline$\geq 2$ medical visits before diagnosis ${ }^{\mathrm{e}}$ & $112(34 \%)$ & $19(17 \%)$ & $\begin{array}{l}\text { 4.46 (2.03, } \\
9.83)\end{array}$ & 0.0002 \\
\hline $\begin{array}{l}\text { Days between onset and isolation } \\
\text { (continuous) }^{f}\end{array}$ & $-{ }^{f}$ & $-{ }^{f}$ & $\begin{array}{l}1.08(1.01, \\
1.16)\end{array}$ & 0.1734 \\
\hline \multicolumn{5}{|c|}{$\begin{array}{l}\text { a Models adjusted for age group and gender, but no other risk factor. Only risk factors with } \geq 5 \\
\text { contagious cases were considered. }\end{array}$} \\
\hline \multicolumn{5}{|c|}{ b P-value corrected for multiple testing through the Holm-Bonferroni method. } \\
\hline \multicolumn{5}{|c|}{${ }^{\mathrm{C}}$ mean: 48.3 years, standard deviation: 17.6 years } \\
\hline \multicolumn{5}{|l|}{ d mean: 23.9 , standard deviation: 4.2} \\
\hline \multicolumn{5}{|c|}{ e mean: 1.5 visits, standard deviation: 0.9 visits } \\
\hline f mean: 5.0 days, standard deviation: & days & & & \\
\hline
\end{tabular}

\section{Discussion}

The number of cases of COVID-19 outside China has increased greatly $[11,12]$. In contrast, the course of the outbreak in China has plateaued and declined gradually after implementation of robust actions. As an international metropolis which is the largest city in China, Shanghai stayed open to the outside during the outbreak and still made great achievements in curbing the epidemic. Breaking the chains of transmission acts as the key to controlling the outbreak. This study examined the epidemiological characteristics of 61 clusters identified in Shanghai to inform an evidence-based control strategy for the global community.

Several features were associated with contagiousness, and therefore could be a target for disease control efforts in locations with limited resources. Upper respiratory symptoms, like sore throat or runny nose, were either significantly associated with contagiousness or were near this border. These symptoms could represent increased viral replication in the upper respiratory tract [13], which could be associated with more or more efficient shedding of virus. We also found that individuals with a severe clinical presentation had greater contagiousness, which could be related to increased viral load.

Delays in diagnosis or isolation were also associated significantly (or near significantly) with contagiousness. This represents failures to control disease spread within the community. The inability to 
rapidly diagnose individuals and insure isolation could explain difficulties controlling disease in locations like the US [14].

Familial transmission was the main type in Shanghai and is consistent with other regions in China. The median of serial interval was 5.50 from the 28 explicit transmission chains we identified, which is relatively shorter than the findings from $\mathrm{Li}$ et al.'s analysis of five clusters ( $7.5 \pm 3.4$ days, $95 \% \mathrm{Cl}, 5.3$ to 19) [15]. We included chains potentially transmitting during an incubation period, which could partly explain the difference. In addition, we observed greater variability of the serial interval when two generations were not in continuous contact. Two peaks emerged at 1-3 days and 11-13 days. Since no significant change has been observed in the genetic makeup of the virus [16], we thought the variability might be mainly due to the exposure situation and incubation period of the two generations, which warrants further study with more transmission chains.

As an international metropolis, Shanghai has curbed COVID-19 even after resuming work. This could be credited to the holistic measures of prevention and control taken. We explored the timeliness and effectiveness of policies, and note that the local government initiated their first-class response to public health emergences after 3 clusters had been identified in the city.

The comprehensive approaches undertaken in the "first-class response" in Shanghai included immediate detection and isolation of cases, precise management of people arriving in Shanghai according to the risk of their origin, rigorous tracing of close contacts, and insuring community compliance with restriction of movement. Shanghai also encouraged social distancing (e.g., working from home, closing schools, limiting mass gatherings and public events) and implemented mandatory and voluntary quarantine through active surveillance. Individual behaviors, such as promoting hand hygiene and the wearing of masks, were also included in this response [17].

Examination of the outbreak's epicurve shows that initial achievements were made in about half an incubation period (7 days) after adopting the first-level response measures. The number of clusters fell from the peak and the outbreak has been generally contained since February 14 . The city resumed work on February 10 , after 11 consecutive days of a decline following the peak on January 30 . Early and precise implementation of prevention and control measures was vital to controlling the epidemic.

\section{Limitations}

Our study has limitations. First, the information extracted from field investigation was inevitably influenced by recall bias and reporting bias of the respondents. Second, the source of infection could not be clearly defined in each of the patients, which brought difficulties in our analysis. Third, the relatively low number of cases in Shanghai limits the statistical power of our analyses.

\section{Conclusions}


In conclusion, COVID-19 has spread widely and brought a huge impact on people's daily life worldwide. In the absence of a vaccine and cure, the Chinese government has implemented several public health actions to contain the spread of virus. Extending the Chinese New Year holiday, for instance, was temporally associated with a decline in the number of clusters. Yet even after resuming work, the number of clusters remained consistently low. The practical experience of Shanghai can be a reference point for other global cities faced with outbreaks of COVID-19 in the future.

\section{Declarations}

\section{Ethics approval and consent to participate}

This study was reviewed and approved by the Shanghai Municipal CDC Ethical Review Committee. Cases were not given an informed consent form as the data were collected as part of on-going public health surveillance.

\section{Consent for publication}

Not applicable.

\section{Availability of data and materials}

The datasets analyzed during the current study are not publicly available due to the reason that these data came from COVID-19 surveillance system in China but are available from the corresponding author on reasonable request.

\section{Competing interests}

The authors declare that they have no competing interests.

\section{Funding}

This work was supported by the Shanghai Municipal Science and Technology Commission (Epidemiological Study on COVID-19 in Shanghai, grant number 20411950100) and Fudan University (Fudan University Research Project on COVID-19 Emergency, grant number IDF201007). The funding bodies had no role in the design of the study, data collection, analysis, interpretation of data, or in writing the manuscript.

\section{Authors' contributions}

HP and XS conceived of the study, helped draft initial manuscript, and analyzed data. DK, QF and LH drafted initial manuscript and analyzed data. HW, YZ, and XG led investigations and contributed substantively to manuscript. ALW and YL revised manuscript substantively and helped interpret data. $Y Z$, BJ, WX, SM, SL, RH, and XY collected data, and interpreted data for analysis. PC and CJ revised manuscript and interpreted data for analysis. All authors reviewed the final manuscript. 


\section{Acknowledgements}

We thank all the investigators in Shanghai for their contribution to the control and prevention of the COVID19 epidemic.

\section{References}

1. Harapan H, Itoh N, Yufika A, et al. Coronavirus disease 2019 (COVID-19): A literature review. J Infect Public Health. 2020; 13(5):667-673.

2. Tu W, Tang H, Chen F, et al. Epidemic Update and Risk Assessment of 2019 Novel Coronavirus - China, January 28, 2020. China CDC Wkly. 2020; 2(6):83-86.

3. World Health Organization. WHO Director-General's opening remarks at the mission briefing on COVID19 - 11 March 2020 [Internet]. 2020 [cited 2020 Mar 18]. Available from:

https://www.who.int/dg/speeches/detail/who-director-general-s-opening-remarks-at-the-missionbriefing-on-covid-19--26-february-2020

4. China Daily. Fourth passenger from cruise ship dies in Japan - NHK [Internet]. 2020 [cited 2020 Mar 18]. Available from:

https://www.chinadaily.com.cn/a/202002/25/WS5e549312a31012821727a1fb.html

5. China Daily. S. Korea reports 115 more coronavirus cases, brings total to 1,261 [Internet]. 2020 [cited 2020 Mar 18]. Available from: http://global.chinadaily.com.cn/a/202002/26/WS5e55c759a31012821727a581.html

6. Cheng S, Zhao R. Prisons in 3 provinces see surge in coronavirus cases [Internet]. China Dly. 2020 [cited 2020 Mar 18]. Available from: https://www.chinadaily.com.cn/a/202002/21/WS5e4f6696a3101282172794af.html

7. Special Expert Group for Control of the Epidemic of Novel Coronavirus Pneumonia of the Chinese Preventive Medicine Association. An update on the epidemiological characteristics of novel coronavirus pneumonia \COVID-19囚. Zhonghua Liu Xing Bing Xue Za Zhi. 2020; 41(2):139-144.

8. China Centers for Disease Control and Prevention. Protocol of prevention and control for novel coronavirus pneumonia (Fifth Version) [Internet]. [cited 2020 Mar 18]. p. 1-57. Available from: http://www.chinacdc.cn/jkzt/crb/zl/szkb_11803/jszl_11815/202002/W020200223341563346503.pdf

9. Chinese Center for Disease Control and Prevention. Cluster Investigation Technical Guideline for the 2019 Novel Coronavirus Pneumonia (COVID-19凶,China (1st Trial Version). Chin J Epidemiol. 2020; 41:293-295.

10. Novel Coronavirus Pneumonia Emergency Response Epidemiology Team. The Epidemiological Characteristics of an Outbreak of 2019 Novel Coronavirus Diseases (COVID-19) - China, 2020. China CDC Wkly. 2020; 2(8):113-122.

11. Callaway E. Time to use the p-word? Coronavirus enters dangerous new phase [Internet]. Nature. 2020 [cited 2020 Mar 18]. Available from: https://www.nature.com/articles/d41586-020-00551-1 
12. Cohen J, Kupferschmidt K. The coronavirus seems unstoppable. What should the world do now? [Internet]. Science (80-. ). 2020 [cited 2020 Mar 18]. Available from:

https://www.sciencemag.org/news/2020/02/coronavirus-seems-unstoppable-what-should-world-donow

13. Tang Y, Schmitz JE, Persing DH, Stratton CW. Laboratory Diagnosis of COVID-19: Current Issues and Challenges. McAdam AJ, editor. J Clin Microbiol. 2020; 58(6):1-9.

14. Mervosh S, Fernandez M. 'It's Like Having No Testing': Coronavirus Test Results Are Still Delayed - The New York Times [Internet]. New York Times. 2020 [cited 2020 Sep 7]. Available from: https://www.nytimes.com/2020/08/04/us/virus-testing-delays.html

15. Li Q, Guan X, Wu P, et al. Early Transmission Dynamics in Wuhan, China, of Novel CoronavirusInfected Pneumonia. N Engl J Med. 2020; 382(13):1199-1207.

16. World Health Organization. Report of the WHO-China Joint Mission on Coronavirus Disease 2019 (COVID-19) [Internet]. 2020 [cited 2020 Mar 18]. Available from: https://www.who.int/docs/defaultsource/coronaviruse/who-china-joint-mission-on-covid-19-final-report.pdf

17. Chen S, Yang J, Yang W, Wang C, Bärnighausen T. COVID-19 control in China during mass population movements at New Year. Lancet. 2020; 395(10226):764-766.

\section{Figures}




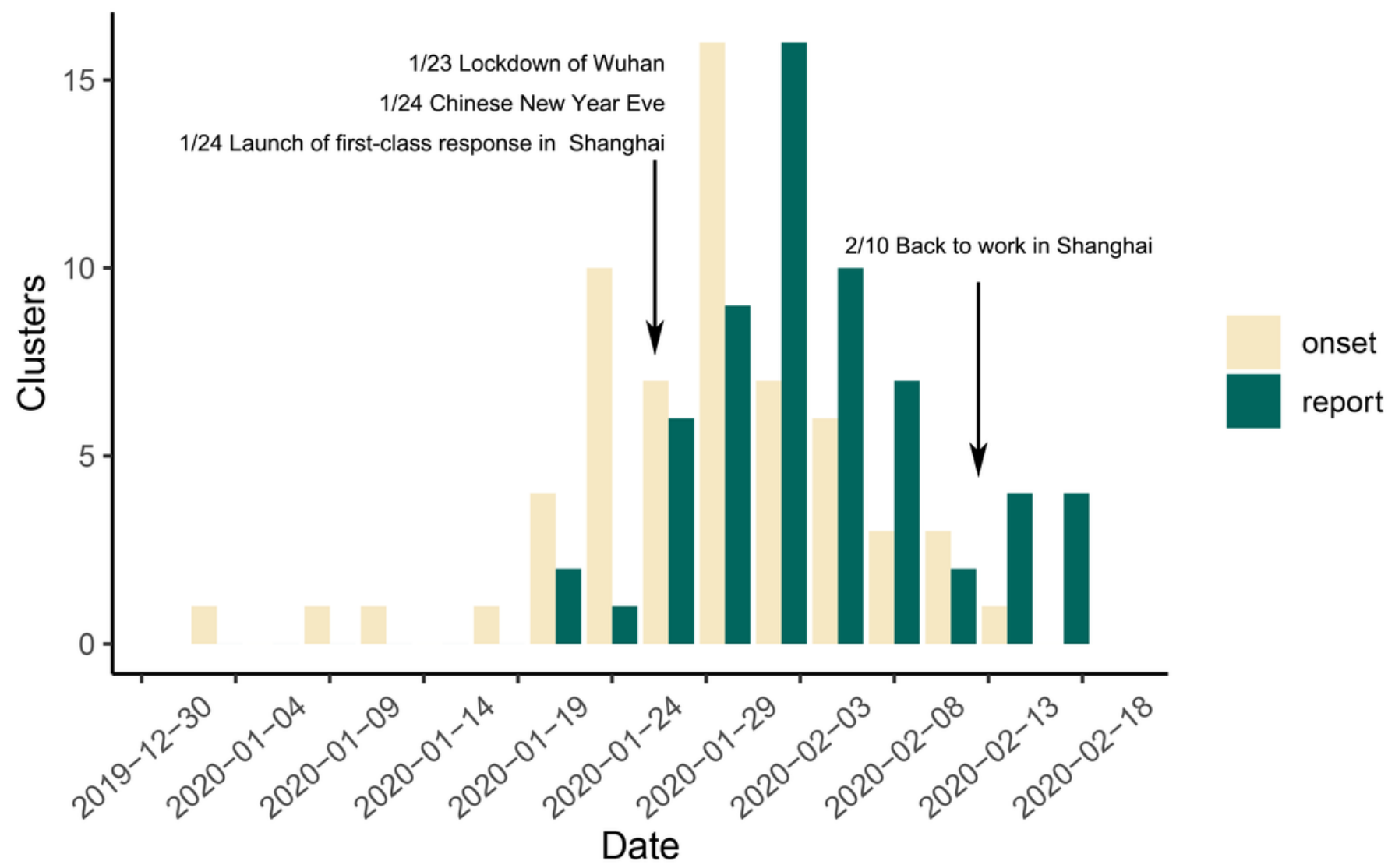

Figure 1

Onset and reported clusters from 28 chains of infection in Shanghai. 
2 patients

Relatives and friends

3 patients

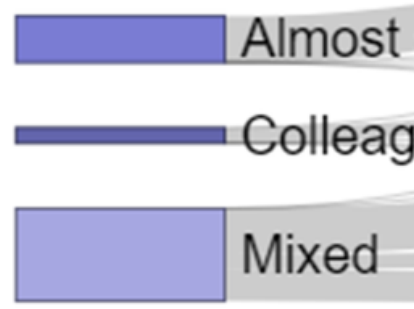

Types of clusters
4 patients

5 patients

$\geq 6$ patients

Number of patients involved

Figure 2

Transmission features of clusters in Shanghai. 


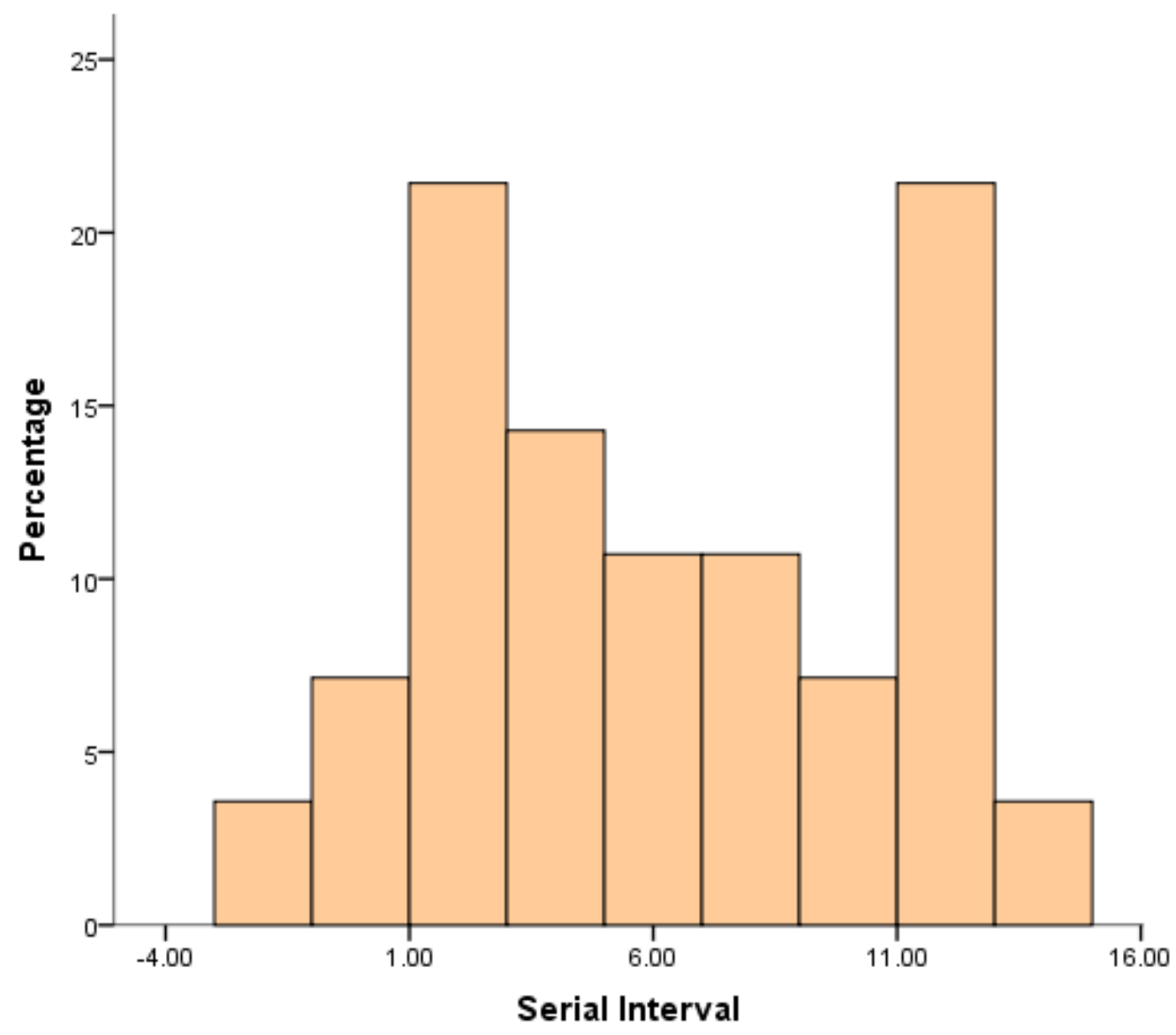

Figure 3

Serial intervals from 28 chains of infection in Shanghai. 


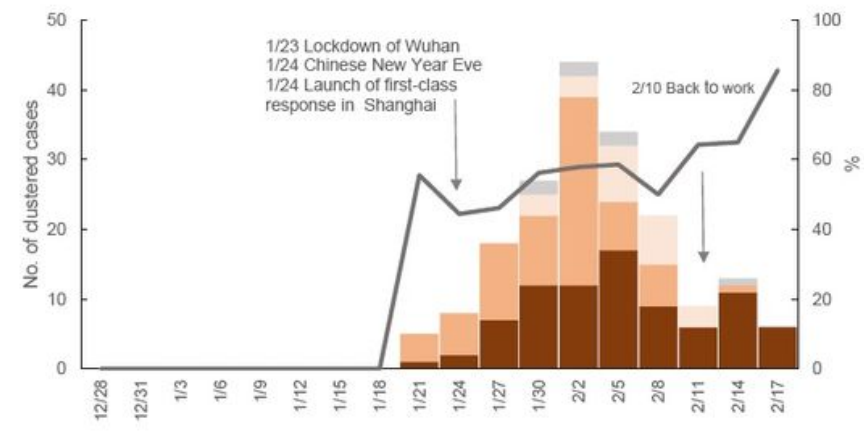

- Shanghai $=$ Hubei Other regions $=$ Unknown $\longrightarrow$ Percentage in all confirmed cases

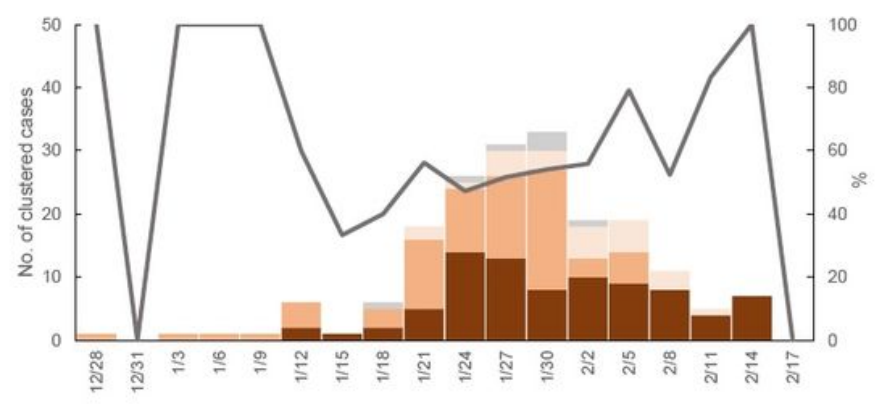

- Shanghai $=$ Hubel Other regions onset

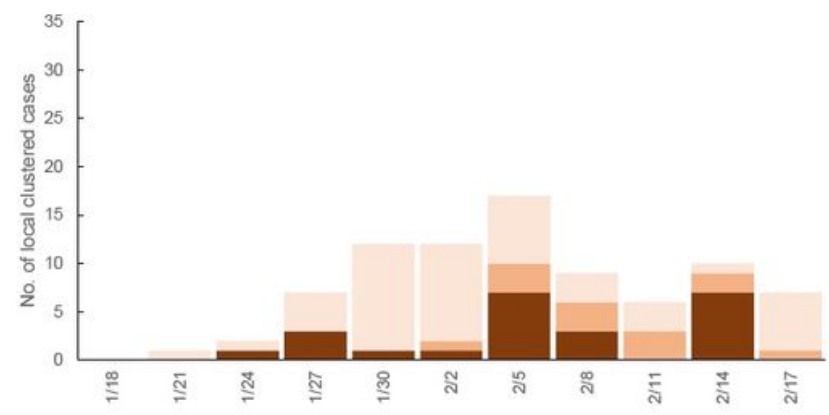

- Community $\begin{gathered}\text { Date of report } \\ \text { =Collective isolation } \quad \text { Sell-discovery }\end{gathered}$

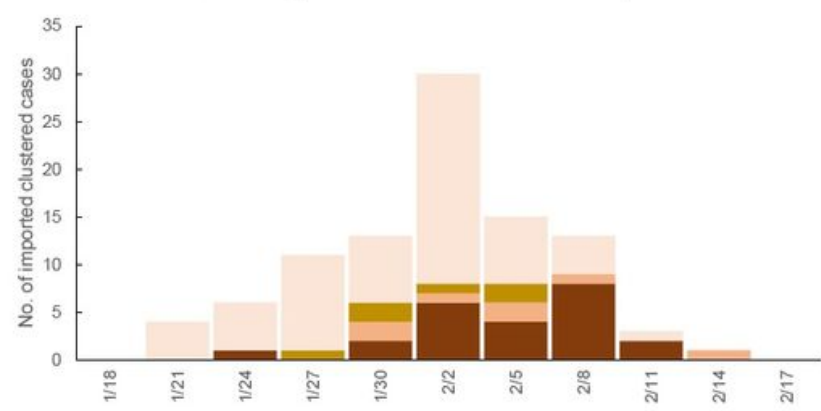

Date of report

Self-discovery

Figure 4

Regions and report routes of clustered cases. 